\title{
The dark side of team social cohesion in NPD team boundary spanning
}

\author{
Pilar Carbonell \\ School of Administrative Studies, Atkinson Building, \\ Room 282, 4700 Keele Street, Toronto M3J 1P3, Canada. \\ E-mail: pilarc@yorku.ca, Tel: 1-416-736-2100 ext. 66303. \\ Ana I. Rodríguez Escudero \\ Facultad de CC.EE. y Empresariales, \\ Avda. Valle Esgueva, nº 6, 47011 Valladolid. \\ E-mail: ana@eco.uva.es, teléfono 983184394
}

This is the accepted version of the manuscript: Carbonell, P. y Rodríguez-Escudero, A.I.. (2019): The dark side of team social cohesion in NPD team boundary spanning, Journal of Product Innovation Management, 36 (2), 141-171. https://doi.org/10.1080/19368623.2019.1564106

\section{Funding}

The authors are grateful for the financial support of the Junta de Castilla y León (Spain), project reference VA112P17, and the Ministerio de Economía, Industria y Competitividad, Plan Estatal de Investigación Científica y Técnica y de Innovación 2013-2016, project reference ECO201786628-P. 


\section{Introduction}

In today's hypercompetitive and fast-paced environment, new product development (NPD) performance depends, more than ever, on a team's ability to span boundaries and forge relationships with parties external to the team, a phenomenon known as team boundary spanning

(Ancona et al., 2009). Team boundary spanning represents a team's actions to establish links and manage interactions with individuals and groups inside and outside the organization with the purpose of coordinating NPD activities, obtaining information and resources and building support for the team and the NPD project (Ancona et al., 2009; Joshi et al., 2009). Research in NPD has shown that team boundary spanning activity positively influences a number of new product outcomes such as adherence to budgets and schedules and project technical quality (Ancona and Caldwell, 1992; Howell and Shea, 2006). This study offers new insights on the influence of team boundary spanning on the success of new products by examining its impact on new product competitive advantage. Product advantage has been shown be the strongest predictor of new product success in Henard and Szymanski (2001) and Evanschitzky et al. (2012) meta-analyses of success factors in product innovation.

Team boundary spanning connects a NPD team to highly valued resources from external parties such as information, feedback on progress and support which, according to research in NPD, can increase a team's ability to develop new products with a competitive advantage (Garcia et al., 2008; Kim and Atuahene-Gima, 2010, Potter and Lawson, 2013; Veldhuizen et al., 2006). However, for boundary-spanning teams, having access to external information and resources may not be enough to deliver product advantage, unless team members integrate the information and resources gained through their boundary spanning work into the NPD project (Maurer et al., 2011). On this point, recent work on boundary spanning suggests that boundary 
spanning teams can be differentially receptive to information and resources coming from outside depending on their psychological characteristics (Dokko et al., 2014; Oh et al., 2004; 2006). As it is argued in detail in this article, one psychological characteristic likely to negatively influence boundary spanning teams' motivation to use external resources is team social cohesion. Team social cohesion refers to the degree to which team members "are attracted to one another and are motivated to stay in the group" (Bettenhausen, 1991, p. 361). Within the literature in social identity, it has been argued that team social cohesion induces a strong team identity among group members and in doing so it elicits intergroup bias (Petersen et al., 2004; Rosenberg and Treviño, 2003), a systematic tendency to evaluate one's group (the in-group) and its members more favorably than other groups (the out-groups) (Hewstone et al., 2002). Drawing on this research, the current study contends that when social cohesion is high, the intergroup biases inherent in highly cohesive groups, would prejudice boundary spanning teams against absorbing and using the information and resources generated through their boundary spanning work, ultimately limiting the potential of these activities to facilitate new product competitive advantage.

Social identity research has argued that socially cohesive groups will exhibit higher intergroup bias in situations in which external actors present a perceived threat to the group's collective identity (Turner and Pratkanis, 1998). Because cohesive groups present a strong group identity along with a strong desire to protect it, in instances where the group identity is threatened by external groups, cohesive groups would tend to maintain their positive image by displaying stronger negative biases toward outgroup members (Turner et al., 1992; Turner and Pratkanis, 1998). For a socially cohesive NPD team, external task interdependence and project newness are two situational project characteristics susceptible of creating situations such the one described above (Glynn et al., 2010; Janssen, 2004). External task interdependence refers to a 
situation in which a NPD team has to rely on external parties to successfully complete their project. A NPD team working under conditions of high external interdependence depends on the cooperation and information of individuals and groups external to the team to effectively do its job (Drach-Zahavy and Somech, 2010). For highly cohesive teams, the work constraints and loss of control that arise from having to consult and collaborate with individuals and groups outside the team can be perceived as a threat to the group's sense of identity (Glynn et al., 2010; Langfred, 2000). Regarding project newness, literature on resistance to change has contended that teams in charge of highly innovative projects do often fall into conflict with and experience resistance from other individuals inside and outside the company due to the wide range of changes brought about by this type of projects (Janssen et al., 2004). For highly cohesive groups, such resistance from outgroup members is likely to be viewed as an attack on the group's objectives and therefore on their collective identity (Janssen, 2004). Drawing on the view that external task interdependence and project newness can provide a context in which external actors are perceived as threats to the identity of highly cohesive teams, the current study expects team social cohesion to have a stronger negative moderating effect on the relationship between team boundary spanning and new product competitive advantage when external task interdependence and project newness are high than when they are low.

The current study makes several contributions to the literatures on team boundary spanning, NPD and social identity. First, findings from this study shed new insights on the significance of team boundary spanning to the success of new products by revealing that boundary spanning activities is beneficial to achieving new product competitive advantage. Secondly, by investigating how boundary spanning's effectiveness is contingent on the level of team social cohesion, this study not only addresses recent calls to examine how team internal characteristics 
interact with team boundary spanning to affect team performance (Marrone, 2010) but also provides a new perspective into the impact of team social cohesion on NPD teams. Thus, within the field of NPD, social cohesion has been primarily viewed as a desirable criterion for team formation and a predictor of new product performance (Im et al., 2013; Nakata and Im, 2010; Shaner et al., 2016). The current study departs from existing research in that it exposes a dark side of team social cohesion for NPD teams engaged in boundary spanning activities. Drawing on social identity theory (Hogg and Abrams, 1988; Petersen et al., 2004; Tajfel and Turner, 1986), the current study argues that team social cohesion can undermine the positive effect of team boundary spanning on new product competitive advantage by decreasing the propensity of team members to consider and integrate the information and resources gathered through their boundary spanning work. To our knowledge, this is the first study to propose a negative synergy between team boundary spanning and team social cohesion. Lastly, the current study expands research on social identity and intergroup bias by proposing and demonstrating that project newness and external task interdependence bring about situations in which external groups present a threat to the collective identity of socially cohesive groups. Thus, while research in this field has argued that, in instances where the collective identity of socially cohesive groups is threatened, these groups are expected to show greater intergroup bias (Rosenberg and Tevino, 2003; Rempel and Fisher, 1997), empirical evidence on this subject has been inconsistent (Turner and Horvitz, 2001). According to Turner and Pratkanis (1998), one explanation for these contradictory findings lies in the nature of the threats used in the literature. In particular, it has been noted that the threats used in a number of studies, while alluding to some form of crisis, presented very little consequences for the effective functioning of the group and thus lacked realism (Turner and Pratkanis, 1998). The current study maximizes the possibility of observing 
threat effects by examining two situational contexts with genuine potential to pose serious threats to the identity of socially cohesive teams, mainly external task interdependence and project newness. Building on the view that external task interdependence (Glynn et al., 2010) and project newness (Janssen, 2003 and 2004) give rise to situations in which socially cohesive teams may perceived that their sense of identity is under threat, it is argued that social cohesion's detrimental effect on the relationship between team boundary spanning and new product competitive advantage would become more pronounced when external task interdependence and project newness are high than when they are low.

\section{Theoretical framework}

The theoretical model depicted in Figure 1 builds upon research on team boundary spanning, NPD and social identify theory.

Marrone (2010) defined team boundary spanning as a team's effort to establish links and manage interactions with individuals and groups inside and outside the organization in an effort to facilitate team goals and objectives. Team boundary spanning encompasses an array of different activities, mainly ambassador, scouting and task coordination (Ancona and Caldwell, 1992; Marrone, 2010). Ambassador activities pertain to building support for the project and the team by talking the NPD project up and forming relationships with external parties. Task coordination activities involve negotiating ad-hoc resources, co-solving problems, and coordinating NPD activities with groups inside and outside the organization. Scouting activities are directed at gaining project-related information such as stakeholder's expectations and market and technological opportunities and trends (Ancona et al., 2009; Marrone, 2010). In this study, team boundary spanning is expected to have a positive effect on new product competitive advantage (see Figure 1). The proposed positive effect is based on NPD research suggesting that 
access to external knowledge and resources can increase a NPD team's ability to develop new products with competitive advantage (Garcia et al., 2008; Kim and Atuahene-Gima, 2010, Potter and Lawson, 2013; Veldhuizen et al., 2006).

Social identity theory asserts that individuals derive satisfaction and value from their group memberships and hence groups and their members are motivated to adopt and maintain positive group identities (Tajfel, 1982; Tajfel and Turner, 1986). Such preference to uphold a favorable group identity is believed to create and sustain intergroup bias (Aberson et al., 2000; Hewstone et al., 2002; Leonardelli and Brewer, 2001, Rosenberg and Treviño, 2003). The more salient a group membership is to its members, the more motivated group members will be to protect or even enhance that identity by showing attitudes and behaviors that favor one's group and derogate other groups (Hewstone et al., 2002; Tajfel and Turner, 1979). According to social identity theory, highly cohesive groups, where individuals have high team identification (Brockman et al., 2010), are too expected to show intergroup bias (Hogg and Abrams, 1988; Petersen et al., 2004; Tajfel and Turner, 1986). High cohesiveness induces a strong sense of unity among members of a group; this perception of unity can be accompanied by a strong sense of differentiation with respect to an outgroup (Dion, 1973). "Once generated, this differentiation of ingroup from outgroup may strongly dominate individuals' perceptions and behavior in intergroup situations evoking contrasting modes of behavior and negative attitudes toward outgroups" (Dion, 1973, p. 169). The current study draws on this research to propose a negative moderating effect of team social cohesion on the relationship between team boundary spanning and new product competitive advantage. In particular, we argue that when team social cohesion is high, the intergroup biases present in highly cohesive groups would prejudice boundary spanning teams against absorbing and using information and resources stemming from those 
activities, ultimately limiting the potential of team boundary spanning to deliver competitive advantage.

Finally, social identity theory suggests that socially cohesive groups will exhibit stronger biases toward outgroup members in situations where group identity is threatened by out-groups (Turner et al., 1992; Turner and Pratkanis, 1998). Because cohesive groups exhibit a strong group identity along with a strong desire to protect their identity, in instances where the collective identity is threatened by out-groups, cohesive groups would tend to maintain their positive image by displaying stronger negative bias toward out-groups (Turner et al., 1992; Turner and Pratkanis, 1998). Extending this line of research, the current study proposes that external task interdependence and project newness create such instances in which external groups can pose a threat to the identity of socially cohesive teams (Glynn et al., 2010; Janssen, 2004), and thus socially cohesive teams are expected to exhibit higher in-group favoritism and out-group derogation when external task interdependence and project newness are high rather than when they are low. Approaching external task interdependence and project newness as situations in which out-group members can pose a significant threat to the identity of highly cohesive teams is something relatively new in the innovation literature. One exception is Glynn et al. (2010), which contended that high identification within the team may lead individuals to view external task interdependence as a threat to their team's identity. Regarding project newness, Janssen and colleagues (Janssen 2003; Janssen 2004; Janssen et al., 2004) have asserted that while it is expected that new ideas introduced by innovative employees generate resistance from other employees, to highly job-involved individuals, resistance from co-workers is likely to be interpreted as an identity-relevant value clash. Building on the view that external task interdependence (Glynn et al., 2010) and project newness (Janssen, 2003 and 2004) give rise 
to situations in which other teams can pose a challenge to the identity of one individual or team, the current study argues that social cohesion would exert a stronger negative moderating effect of team cohesion on the relationship between team boundary spanning and new product competitive advantage when external task interdependence and project newness are high than when they are low.

\section{Hypotheses}

Team boundary spanning and new product competitive advantage

New product competitive advantage is defined as "a product's perceived superiority relative to competitive products" (Song and Montoya-Weiss, 2001; p. 65). Team boundary spanning activity is expected to positively impact new product competitive advantage based on the following reasons. First, building relationships with existing and potential customers can give NPD teams an opportunity to better understand customers' needs and wants and to clarify expectations (Ancona and Caldwell, 1988), improving their ability to deliver superior products (Li and Calantone, 1998). Also, establishing relationships with suppliers, distributors, and research centers can improve a NPD team's access to up-to-date market and technological information and trends, which is deemed critical to create new products with innovative and superior features ( $\mathrm{Li}$ and Calantone, 1998). Furthermore, boundary spanning activities can provide NPD teams with timely and critical feedback from groups inside and outside the company on the NPD project, which has been shown to heighten a NPD team's ability to produce superior new products (Menon et al., 1997). Therefore, we propose that:

H1: Team boundary spanning will have a positive effect on new product competitive advantage Moderating effect of team social cohesion on the relationship between team boundary spanning and new product competitive advantage 
We expect team boundary spanning to be more strongly related to new product competitive advantage when team social cohesion is low than when it is high. Central to the social identity theory is the idea that group members with a strong group identity are most susceptible to developing intergroup bias (Hogg and Hains, 1996). When group identity is salient, fostering hostile attitudes, stereotypes and rivalry toward outgroups are likely means by which group members can enhance their own group's image (Richter et al., 2005; Rosenberg and Treviño, 2003). Consistent with social identity theory, highly cohesive groups, where individuals have high team identification (Brockman et al., 2010), are then expected to show intergroup bias (Hogg and Abrams, 1988; Petersen et al., 2004; Tajfel and Turner, 1986). For example, Dion (1973) found that members of highly cohesive groups were more cooperative towards their team members than toward members of out-groups and evaluated their team members more positively than out-group members. Drawing on the previous discussion, we argue that when team social cohesion is high, the intergroup biases present in highly cohesive groups would diminish the propensity of boundary-spanning teams to integrate into the NPD project information and resources gathered via team boundary spanning, reducing the potential of these activities to deliver new product competitive advantage. Despite the lack of empirical evidence, accounts from a few studies provide support for this hypothesis. Oh et al. (2004, 2006) observed that whereas strong-closure groups have relationships with others outside the group, the information and resources that flow through those relationships are generally disregarded when they enter the group due to the presence of positive in-group biases and negative out-group biases. Similarly, Dokko et al. (2014) noted that in cases where team identity is high (such as in socially cohesive teams), team members are more inclined to focus inwardly on group's matters and pay less attention to information and resources from outside. Finally, Chung and Jackson (2013) argued 
that when bonds among team members are very strong, "the team may develop a cognitive barricade that shuts out useful information from the external world" (p. 446). Therefore, we propose that:

H2: Team social cohesion will have a negative moderating on the relationship between team boundary spanning and new product competitive advantage.

Impact of external team interdependence and project newness on the moderating effect of team social cohesion

According to social identity research, socially cohesive groups will exhibit greater negative bias toward outgroup members in contexts where such individuals and groups are perceived as a threat to the group identity (Turner and Pratkanis, 1998). The current study views external task interdependence and project newness as two project characteristics susceptible of creating a context in which external actors are perceived as threats to the identity of highly cohesive teams and thus it expects external task interdependence and project newness to accentuate the negative moderating effect of team social cohesion on the relationship between team boundary spanning and new product competitive advantage.

External task interdependence refers to the extent to which team members need to work with individuals and groups inside and outside the organization to complete their NPD project and make project-related decisions (Drach-Zahavy and Somech, 2010). There are number of reasons why external groups can pose a threat to the identity of socially cohesive groups when external task interdependence is high. First, external task interdependence requires team members to coordinate with others in the delivery and/or receipt of information, resources and expertise for the completion of the project (Glynn et al., 2010). For highly cohesive groups, the need to coordinate is expected to raise the group perception that external groups represent a threat to the 
goals and interests of their own group (Williams, 2001). Second, external task interdependence may cause socially cohesive group to lose its distinctiveness. The more team members establish links between the group and others, the more likely it becomes for the team boundaries to become permeable (Choi, 2002; Langfred, 2000). According to social identity theory, a decrease in the salience of the team boundaries will reduce both the mutually perceived identity among group members as well as their perceived dissimilarity from outgroups (Tajfel and Turner, 1986). Finally, external task interdependence reduces NPD team's latitude in executing the NPD project. External task interdependence means that the responsibility for project planning and implementation does not solely fall on the group itself but is shared with others. This lack of control over assigned tasks and project decisions threatens the team's collective identity by causing group members make inferences about the status of the group relative to other groups in the organization (Langfred, 2000; Man and Lam, 2003). Drawing on the previous discussion, we expect highly cohesive teams to show greater positive ingroup bias and higher negative outgroup discrimination when external task interdependence is high than when it is low. In support of this hypothesis, Riccobono et al. (2016) noted that in highly cohesive teams, a lack of internal control over project decisions (i.e., a trait of externally dependent NPD projects) accentuated a group's motivation to disregard any involvement or suggestions coming from the outside. Thus, we propose that:

H3: External task interdependence will increase the negative moderating effect of team social cohesion on the relationship between team boundary spanning and new product competitive advantage.

Project newness or innovativeness refers to the potential discontinuity a new product can generate in a firm's technological and marketing processes. Highly innovative products offer a 
high level of discontinuity by involving new processes and technologies as well as product categories, competitors, distributor channels and customers that are unfamiliar to the firm (McNally et al., 2010). Because of the discontinuity focus of highly-innovative products, NPD teams developing highly innovative NPD projects are more likely to encounter conflict with and resistance from other groups and individuals inside and outside the organization. Thus, literature on resistance to change has noted that people in the workplace generally tend to resist change because of the insecurity and uncertainty that it brings. Also, because habits and preferences for familiar practices and actions are hard to break (Janssen, 2004). Against this backdrop, we argue that for highly cohesive groups developing high-innovative products, resistance from outgroup members will be conceived as an attack to the team's collective identity in the sense that team's efforts to successfully advance highly-innovative projects will be most likely obstructed by outgroups. Consequently, socially cohesive groups are expected to show greater negative bias against outgroups when developing highly innovative products than low innovative products.

H4: Project newness will increase the negative moderating effect of team social cohesion on the relationship between team boundary spanning and new product competitive advantage.

\section{Methodology}

\section{Sample and data collection}

Data for this study were collected from Spanish manufacturing firms. The sampling frame was the Amadeus directory of Spanish firms, which provided a list of 3,786 manufacturing companies across different industrial sectors. In defining the sampling frame, we focused on industrial sectors classified as high technology and medium-high technology by EUROSTAT. The food and beverages manufacturing sector, although classified as low-technology by EUROSTAT, was also included in the sampling frame because of its high values of R\&D 
spending (Cotec, 2016). Also, to maximize the ability to measure a full range of team boundary spanning activities, we only considered firms with 35 or more employees as the limited number of functional departments and hierarchical levels present in small firms may constrain a NPD team's effort to engage in boundary spanning behaviors. We randomly selected 25 percent of the firms in each of the industry groups, which resulted in 946 manufacturing firms.

In order to reduce the presence of common method bias, a decision was made to collect the data in two stages temporally separated (Podsakoff et al., 2003). According to Podsakoff et al., (2003), the introduction of a temporal distance between the measurement of the independent and dependent variables reduces the respondent's ability to use previous answers to answer subsequent questions. Evidence of the effectiveness of introducing a temporal distance between the measurements comes from several studies (Johnson et al., 2011 and Rindfleisch et al., 2008). During the first stage of the data collection, a questionnaire focused on boundary spanning activities of NPD teams was mailed to each of the companies in our database. This questionnaire was addressed to the person in the company responsible for NPD activities. Respondents were instructed to answer the survey questions with regard to a recently completed NPD project that they had led or managed. It was requested that the product be in the market for at least six months (Im et al., 2013). Also, at this point, potential respondents were informed that as part of the same research project, a follow-up questionnaire would be administered at a later date. For this first round, we obtained a total of 146 completed surveys. Data on the remaining variables in the model (i.e., team social cohesion, project newness, external task interdependence, and new product competitive advantage) were collected using a second survey sent by post and email to the 146 firms that had returned the first survey. It is important to note that all respondents were reminded of the new product chosen to answer the first survey and asked to answer the survey 
having the same NPD project in mind. 140 of the 146 firms contacted, completed the second survey. The time lag between the first and second surveys ranged between one to four months. Of the key informants responding to the survey, $45.2 \%$ were R\&D managers, $34.1 \%$ were technical managers, $13.3 \%$ were general managers and $7.4 \%$ were managers of other departments.

Table 1 shows the population and the sample for each industry group. To check for response bias by industry, we applied a two-proportion test to compare the proportions of firms in the sample and the population for each industry group. The results reveal significant differences for the industry group 'computer, electronic and electrical manufacturing' (334 and 335 NAICS codes). Specifically, firms within this group are over-represented in the sample, which is reasonable to expect given that the sectors these firms belong to are high-technology industries. Additionally, for the two rounds of surveys, non-response bias was tested by comparing the responses of early (first third) and late (last third) respondents. No statistically significant differences were found in the mean scores of the main constructs used in this study.

(Insert Table 1 here)

Finally, although concerns about common method bias were mitigated by collecting data on the independent and dependent variables at two different times, we performed the Harman's single-factor test (Podsakoff et al., 2003) to ensure that common method bias was not an issue in this study. Results from this analysis showed twelve factors in the unrotated factor structure, explaining $75.5 \%$ of total variance, with the first factor accounting for only $22.3 \%$. In addition, the correlation matrix shows an average correlation between variables relatively low (0.13). Taken together, results from these two tests suggest that common method variance was not a serious threat. 


\section{Measurement scales}

Research in team boundary spanning has generally viewed team boundary spanning as consisting of three different activities, i.e., ambassador, scouting and task coordination activities, each of them taking place inside the organization (i.e., intrafirm) as well as outside the organization (i.e., extrafirm) (Ancona et al., 2009; Marrone, 2010; Sleep et al., 2015). In keeping with this view, we operationalized team boundary spanning as a formative second-order construct composed of six reflective first-order dimensions, mainly intrafirm ambassador, extrafirm ambassador, intrafirm scouting, extrafirm scouting, intrafirm task coordination and extrafirm task coordination. Measurement items of the six dimensions of team boundary spanning were adapted from Ancona and Caldwell (1988 and 1992) (see Table 2). The appropriateness of the initial pool of 30 items for capturing the multidimensionality of the team boundary spanning construct was tested by performing a series of exploratory factor analyses (principal component with promax rotation). An iterative process was used to eliminate singleitem factors, items with communalities estimates of 0.6 or lower, items with factorial loadings of 0.4 or lower and items with high cross-loadings (Nunnally and Bernstein, 1994). The final factor analysis showed a 27 -item, seven-factor solution with eigenvalues greater than 1 , which together explained $72.76 \%$ of the variance. The exploratory factor solution included two factors related to ambassador activities, three factors about scouting activities and two factors pertaining to task coordination activities. Observe that intrafirm scouting activities were split into two dimensions; one related to scouting general information about the project and another pertaining to scouting specific marketing and technical information for the project.

To further asses the scales' factor structure, we performed a confirmatory factor analysis on the seven-factor solution (SmartPLS 3.1.5). All 27 items had item loadings greater than 0.50 on 
their respective factors thus, all items were retained (see Table 2). As shown in Table 2, Cronbach alphas and composite reliability values of all the team boundary spanning dimensions exceeded the standards of 0.70 . Also, for all the dimensions, the values of the average variance extracted were above 0.50 , hence indicating convergent validity (Hair et al., 2013).

(Insert Table 2 here)

To statistically validate the formative character of the seven dimensions of team boundary spanning scale, we checked for multicollinearity among its dimensions using the varianceinflation factor (VIF). The VIF values of the dimensions were below the cut-off value of 10 (max. VIF: 2.198). Thus, there are no concerns about collinearity issues. Next, we examined the significance of the contribution of each dimension to the main construct. Fit of the formative measurement model was good as evidenced by the fact that the outer weights of all dimensions were significant at $\mathrm{p}<0.01$ (see Table 3 ).

\section{(Insert Table 3 here)}

Established multi-item scales were used to measure the rest of the study's constructs. Team social cohesion was operationalized with a 4-item scale taken from (Sethi et al., 2001). External task interdependence was measured with three items adapted from Sethi (2000) and project newness and product competitive advantage were each measured with 3 -item scales adapted from McNally et al. (2010). The study includes two control variables for new product competitive advantage: firm size and product innovation. Firm size can be considered as a proxy variable of market power and financial resources; larger organizations typically have enough R\&D, marketing and financial resources to successfully develop and commercialize new products and services (Ali et al., 1995). Firm size was measured with the number of employees. Product innovation refers to the weight that a company assigns to the value of new products for 
creating and retaining a competitive position (Zahra, 1993). Firms with high product innovation activity are more likely to collect and disseminate customer and competitor intelligence so that product innovations provide greater value added for customers (Siguaw et al., 2006). Product innovation was measured with three items adapted from Zahra (1993). Measurement items and statistics that confirm the reliability (Cronbach alpha and composite reliability) and validity (average variance extracted) of the scales are shown in Table 4.

(Insert Table 4 here)

Discriminant validity was assessed by examining the square root of the average variance extracted for each construct. Discriminant validity is evidenced when the square root of the AVE for each construct exceeds the corresponding correlations between that construct and any other constructs (Fornell and Larcker, 1981). All possible pairs of constructs passed this test. Henseler

et al.'s (2015) heterotrait-monotrait (HTMT) ratio of correlations technique also indicated discriminant validity, as all HTMT ratios were well below the conservative threshold of 0.85 . Table 5 shows the square roots of AVE on the diagonal, the correlation values below the diagonal and the HTMT ratios above the diagonal.

(Insert Table 5 here)

\section{Data analysis and results}

The proposed model was tested using Partial Least Squares Structural Equation Modeling (PLSSEM) algorithm (Smart PLS 3.1.5). PLS-SEM is preferable to covariance-based SEM (CBSEM) because it better handles small sample sizes and does not make any distributional assumptions to estimate the model (Hair et al., 2013; Reinartz et al., 2009). A further strength of PLS relevant for this study is the ability to handle reflective and formative measures in a single model (Hair et al., 2013). A bootstrap test (1,000 sub-samples) was used to generate the standard 
error and t-values of the parameters. Option "no sign change" was employed for model estimation because it results in the most conservative outcome (Hair et al., 2013).

Variables were introduced into the model hierarchically as blocks. First, we included the direct effects of team boundary spanning, control variables and moderators on new product competitive advantage (Model 1). Then, we added the two-way interaction effect of team boundary spanning and team social cohesion (Model 2). Next, the three-way interaction effect of external task interdependence was included (Model 3) followed by the three-way interaction effect of project newness (Model 4), along with all two-term interaction terms. We chose to incorporate external task interdependence and project newness into separated models in order to control for the increase of Type I error that happens when multiple moderator effects of correlated variables are investigated (Cohen et al., 2013; Frazier et al., 2004). Multicollinearity was examined using VIF statistics and found to be acceptable in all cases. The maximum VIF values for Models 1, 2, 3 and 4 were respectively, 1.196, 1.210, 1.769 and 1.341, which are well below the cut-off point of 10 (Hair et al., 2009). Table 6 contains the results for Models 1-4.

Results for Model 1 in Table 6 show a positive relationship between team boundary spanning and new product competitive advantage $(\beta=0.14, \mathrm{p}<.05)$, which provides support for H1. Also, in support of $\mathrm{H} 2$, we found a significant and negative two-way interaction effect of team boundary spanning and team social cohesion $(\beta=-0.24, \mathrm{p}<.01 \text {, Model } 2)^{\mathrm{i}}$. Following Aiken and West (1991)'s procedure, we calculated the effect of team boundary spanning on new product competitive advantage at one standard deviation below and above the mean of team social cohesion. Results showed a positive and significant effect of team boundary spanning on new product competitive advantage at low level of team social cohesion $(\beta=0.44, \mathrm{p}<.01)$. The effect of team boundary spanning on new product competitive advantage became insignificant at 
high levels of team social cohesion. Results in Models 3 and 4, respectively show significant and negative three-way interaction effects of team boundary spanning, team social cohesion and external task interdependence $(\beta=-0.28, \mathrm{p}<.01)$, and team boundary, team social cohesion and project newness $(\beta=-0.19, \mathrm{p}<.01)$, thus $\mathrm{H} 3$ and $\mathrm{H} 4$ are supported.

(Insert Table 6)

Next, we employed the partial derivative's approach proposed by Schoonhoven's (1981) (Figures 2 and 3) and the Aiken and West's (1991) procedure to determine whether the two-way interaction effect of team boundary spanning, and team social cohesion changed over the range of the external task interdependence and project newness variables. Figure 2 graphically depicts the two-way interaction effect of team boundary spanning and team social cohesion over the range of values of external task interdependence [Eq.(1): ( $d$ new product competitive advantage $/ d$ team boundary spanning $) \times(1 / d$ team social cohesion $)=-0.18-0.28 \times$ (external task interdependence)]. The results in Figure 2 shows that the negative moderating effect of team social cohesion on the team boundary spanning-new product competitive advantage relationship becomes more pronounced as external task interdependence increases. Following Aiken and West (1991)'s procedure, we calculated the moderating effect of team social cohesion on the relationship between team boundary spanning and new product competitive advantage at one standard deviation below and above the mean of external task interdependence. Results showed a non-significant interaction effect of team social cohesion and team boundary spanning at low level of external task interdependence (-1SD). The interaction effect however became significant and negative at high levels $(+1 \mathrm{SD})$ of external task interdependence $(\beta=-0.52, \mathrm{p}<.01)$.

Figure 3 depicts the two-way interaction effect of team boundary spanning and team social cohesion over the range of values of project newness [Eq.(2): ( $d$ new product competitive 
advantage $/ d$ team boundary spanning) $\mathrm{x}(1 / d$ team social cohesion) $=-0.13-0.19 \mathrm{x}$ (project newness)]. In keeping with $\mathrm{H} 4$ prediction, the results in Figure 3 shows a more negative interaction effect between team social cohesion and team boundary spanning as project newness increases. Relatedly, Aiken and West (1991)'s procedure revealed negative and significant moderating effects of team social cohesion on the relationship between team boundary spanning and new product competitive advantage at high (+1SD) levels of project newness $(\beta=-0.51$, $\mathrm{p}<.01)$ and a non-significant moderating effect (-1SD) at low levels of project newness.

(Figure 2 and 3 here)

\section{Additional analysis}

In this work, team boundary spanning was modelled as a second-order formative construct consisting of three different activities, i.e., ambassador, scouting and task coordination, each of them taking place inside as well as outside the organization (Ancona et al., 2009; Marrone, 2010; Sleep et al., 2015). Because of the formative nature of team boundary spanning, ambassador, scouting and task coordination activities are not expected to be strongly correlated. In this context, it was deemed appropriate to conduct additional analyses to determine whether the model proposed in Figure 1 would hold for the three activities of team boundary spanning. Accordingly, we re-run the proposed model for each activity of team boundary spanning separately. The results from these analyses, which are shown in the Appendix, are highly consistent with the results associated with the model that combines the three boundary spanning activities into one single construct. All two-way interactions (i.e., ambassador x social cohesion, scouting x social cohesion and task coordination $\mathrm{x}$ social cohesion) and five of the six three-way interactions (exception made for scouting x social cohesion x project newness) were significant at $\mathrm{p}<0.05$. In sum, the model proposed in Figure 1 is valid for all components of the team 
boundary spanning scale.

\section{Discussion}

Prior research has suggested that team boundary spanning can have a positive effect on the performance of NPD teams (Ancona and Caldwell, 1992; Howell and Shea, 2006). By establishing linkages and managing interactions with parties inside and outside the organization, boundary spanning allows NPD teams to access highly valuable external resources needed for the successful completion of the NPD projects (Ancona and Caldwell, 1992; Marrone 2010). Findings from this study extends research on this subject by revealing a positive effect of team boundary spanning on new product competitive advantage. Our results are consistent with research on NPD suggesting that product advantage depends, in part, on a NPD team's access to external knowledge and resources (Li and Calantone, 1998; Kim and Atuahene-Gima, 2010).

Although team boundary spanning is conducive to achieving new product competitive advantage, these actions may not always deliver the expected performance (Marrone, 2010). The current study makes an initial attempt to examine factors that can reduce team boundary spanning positive effect on new product competitive advantage by proposing and testing a negative moderating effect of team social cohesion on the relationship between team boundary spanning and new product competitive advantage. Team social cohesion has generally been considered a desirable criterion for team formation and a predictor of new product performance (Im et al., 2013; Nakata and Im, 2010; Shaner et al., 2016). Results from this study confirm the above findings by showing that team social cohesion has a positive effect on new product competitive advantage. However, unique to this study is the finding that team social cohesion can reduce the positive effect of team boundary spanning on new product competitive advantage. Thus, the study's results show that whereas team boundary spanning has a positive and 
significant effect on new product competitive advantage when team social cohesion is low; the effect becomes insignificant when social cohesion is high. As argued earlier, teams with high levels of social cohesion are prone to show positive negative outgroup biases (Petersen et al, 2004; Rosenberg and Treviño, 2003). Such biases are likely to prejudice group members against absorbing and using information and resources stemming from boundary spanning activities, ultimately limiting the potential of these activities to deliver competitive advantage.

Moreover, the study's results reveal that project newness and external task interdependence accentuates the negative moderating effect of team social cohesion on the relationship between team boundary spanning and new product competitive advantage. Both project newness and external task interdependence are argued to create a context in which socially cohesive groups would perceive external groups as threats to their collective identity. Regarding project newness, NPD teams developing highly innovative NPD projects are more likely to experience conflict with and resistance from groups and individuals inside and outside the organization because of the wide-ranging changes brought about by these types of products (Janssen, 2004). Accordingly, for highly cohesive groups developing high-innovative products, resistance from outgroup members may be conceived as an attack to the team's collective identity in the sense that resisting groups may obstruct or impede a team's efforts to successfully advance the highlyinnovative project. External task interdependence can also accentuate socially cohesive groups' negative bias against external groups. External task interdependence creates work constraints for the NPD team as team members have to coordinate with others to be able to complete their job. Also, external task interdependence may cause teams to lose their distinctiveness and question their status within the organization, threating the team's collective identity (Glynn et al., 2010; Langfred, 2000). Accordingly, under high project newness and external task interdependence, 
highly cohesive teams will tend to disregard externally derived information and resources to the detriment of the new product performance. Interestingly, our results suggest that team social cohesion does not have a significant moderating effect on team boundary spanning when project newness and external task interdependence are low, which suggests that it is the perception of a threat what activates the negative moderating effect of team social cohesion.

\section{Implications}

\section{Theoretical contributions}

Our findings extend previous research in several ways. First, the study contributes to research in team boundary spanning. In her review article of past research on team boundary spanning Marrone (2010) noted: "significant gaps still exist in our understanding of the team boundary spanning phenomenon" (p. 912). In particular, "surprisingly little empirical attention has been paid thus far to possible moderating conditions of the team boundary spanning-team performance relationship" (p. 927). Faraj and Yan (2009), and Gibson and Dibble (2013) are among the very few studies to empirically test and find moderators of this relationship. By investigating the moderating effect of team social cohesion in the relationship between team boundary spanning and new product competitive advantage, this study provides new empirical evidence about when team boundary spanning influences new product performance. Furthermore, by incorporating team social cohesion in our model, the current study supports the emerging recognition that team psychological factors are important to the effectiveness of a team's boundary spanning efforts (Dokko et al., 2014).

In addition, the current study brings a new perspective to the discussion of the effect of team social cohesion on NPD performance by examining team social cohesion in the context of intergroup relationships (i.e., team boundary spanning). Within the field of NPD, team social 
cohesion has been studied primarily by researchers not so much interested in intergroup relationships but in intragroup processes (Brockman et al., 2010; Im et al., 2013). Within this perspective, it is noted that team social cohesion facilitates integration, communication and information sharing within the NPD team which, in turn, leads to higher new product performance (Im et al., 2013; Nakata and Im, 2010; Shaner et al., 2016). Moreover, wherever a negative effect of team social cohesion on new product performance has been identified, researchers have used groupthink theory to explain their findings (e.g., Brockman et al., 2010; Sethi et al., 2001). Thus, Brockman et al. (2010) noted that high levels of interpersonal cohesiveness can negatively impact new product performance due to team members' unwillingness to express different opinions. Notwithstanding the previous studies, the current study departs from existing research in that it examines the effects of team social cohesion in the context of team boundary spanning (a.k.a. intergroup relationships). In doing so, the current study draws on social identity theory, which predicts that groups with high levels of social cohesion are likely to show high levels of intergroup bias (Hogg and Abrams, 1988; Petersen et al., 2004; Tajfel and Turner, 1986), to suggest that team social cohesion can undermine the positive effect of team boundary spanning on new product competitive advantage.

Finally, the study's results advance the emerging research on group identity and intergroup bias in team boundary spanning (e.g., Dokko et al., 2014; Richter et al., 2006) by showing that the moderating effect of team social cohesion on the relationship between team boundary spanning and new product competitive advantage is accentuated by project newness and external task interdependence. Drawing on social identity research suggesting that socially cohesive groups exhibit a strong motivation to protect the group identity in situations where such identity is threatened by outgroup members (Turner et al., 1992; Turner and Pratkanis, 1998), we propose 
that project newness and external task interdependence bring about such situations, and thus socially cohesive groups are likely to exhibit stronger intergroups bias when project newness and external task interdependence are high than when they are low. Of note is that this is the first study in which these relationships are proposed and tested.

\section{Managerial implications}

Our findings have several implications for managers. First, findings suggest that firms should encourage NPD teams to engage in team boundary spanning activities. Reaching outside NPD teams for the purposes of coordinating activities and obtaining information, knowledge and support can help increase the competitive advantage of new products. In this respect, it is suggested that firms help NPD teams develop their personal networks, as these networks facilitate boundary-spanning activities (Brion et al., 2012). For example, firms could help identify critical contacts, set up networking meetings and follow-up to ensure that the outreach process is underway (Ancona et al., 2009).

Secondly, results from this study reveal that team social cohesion can reduce the positive effects of boundary spanning on new product competitive advantage. One way by which companies may combat the detrimental effects of team social cohesion on the effectiveness of team boundary spanning activities is by enhancing organizational identification (Gaertner et al., 1999; Hogg and Terry, 2000). Thus, Richter et al. (2005) showed that when group members identify strongly with both the group and the organization, relationships with other groups tend to be less conflicting and more productive. Companies can increase organization identification by communicating organizational successes, values and goals (Richter et al., 2005).

Third, the study's results suggest that, in situations of medium and high external task interdependence and project newness, managers of socially cohesive NPD teams should carefully 
attend to team members' perceptions of external groups as threats to their collective identity as these perceptions can hamper the effectiveness of the team's boundary spanning efforts. In situations of high project newness, a team's perception that external groups pose a threat to their collective identity is linked to the tendency of organizations to resist radical innovation. Consequently, a plausible way for managers to overcome this resistance might be to instigate within the company attitudes that foster radical innovation such as willingness to cannibalize, future market orientation, and risk tolerance (Tellis et al., 2009).

In situations of external task interdependence, managers can lower the perceived threat posed by external groups by, for example, attempting to reframe perceived task interdependence as a challenge rather than a constraint. To this effect, Glynn et al. (2010) suggested that in situations where NPD teams perceived high task interdependence, managers can reduce intergroup bias and encourage NPD team members to open up by emphasizing the benefits that can come from cooperating with external parties. Another way of reducing the tendency of cohesive groups to display intergroup bias under external task interdependence is to have interdependent groups share responsibility for the new product outcomes. Thus, Janssen (2003) noted that "shared perceptions of positive goal interdependence not only protect the interdependent parties from the dark side of conflict but may even motivate them to manage the issues at stake in a constructive manner" (p. 360). In support of this notion, Gaertner et al (1990) found that setting interdependent goals increased the extent to which members of separate groups rated their aggregate as a single group and decreased intergroup bias.

\section{Study limitations and future research lines}

The current study has some limitations that should be acknowledged. First, the study uses a key informant approach. In particular, data were provided by managers that led or were in charge of 
new product development projects from beginning to end. While one can expect project leaders to have a great deal of knowledge about NPD teams and their practices (e.g., team boundary spanning), their outlook in matters pertaining to intrateam dynamics and emergent states such as social cohesion could diverge from that of individual team members. It is thus suggested that future studies include multiple informants within one team for a better assessment of the level of team social cohesion. Second, we used a retrospective methodology, which may lead to hindsight bias, project selection bias and recall error (Brockman and Morgan, 2003). Finally, the crosssection design of the survey study prohibits the testing of causality. Longitudinal designs are needed to examine the causal relationships implied in the model.

This study points to some avenues for future research. A fruitful area could be to examine other moderators of the team boundary spanning-new product competitive advantage relationship. For example, unlike the focus of this study on team-related factors that undermine the positive effect of team boundary spanning on new product competitive advantage, future research could examine team-related factors that enhance such relationship by positively influencing a team's propensity to consider externally derived resources. In this respect, a team's psychological safety could play a role (Ancona et al., 2009). For example, research on boundary spanning suggests that engaging in boundary spanning can be perceived as a risky and threatening team's endeavor (Bresman and Zellmer-Bruhn, 2013; Choi, 2002). From this perspective, psychological safety can help team members overcome some of the risks inherent in accessing and presenting external knowledge to the team, ultimately increasing the positive effect of team boundary spanning on new product competitive advantage. Another avenue for future research is to explore other new product outcomes (e.g., creativity, efficiency, market success and speed to market) to offer additional insights into the dark side of social cohesion for 
teams that engage in boundary spanning activities.

Moreover, it would be interesting to explore the intervening variables responsible for the negative moderating effect of team social cohesion, mainly positive ingroup bias and negative outgroup bias. These variables should be examined in future research so that the explanatory mechanisms implicated in our study can be tested more stringently. Furthermore, future studies could examine the potential of organizational identification, interteam goal interdependence and innovative culture to mitigate, respectively, the negative moderating effects of team social cohesion, external task interdependence and project newness. As stated earlier, for social cohesive teams, managers may combat ineffective intergroup relationships by increasing team members' identification with the organization (Richter et al., 2006). Interteam goal interdependence and innovative culture, respectively, can also be effective in decreasing a team's perception of the perceived threat posed by contexts of medium and high external task independence and project newness.

Also, the variable of interest in this research, team social cohesion, is only one element of the general construct of team cohesion; the other being, task cohesion. Task cohesion is a group's shared commitment or attraction to the group task or goal (Goodman et al., 1987). Prior research on group cohesion has suggested that the goals and objectives of socially cohesive groups are different from those of task-oriented cohesive groups. For example, according to Bernthal and Insko (1993) whereas, the driving force behind socially cohesive groups are maintenance of selfesteem and emotional balance, task-oriented cohesive groups are mostly driven by rigorous evaluation and objective discussion. From this perspective, task-oriented groups would be expected to show little or none negative bias against external groups. Future studies are encouraged to examine these differences by incorporating task cohesion into the proposed 
model.

Finally, there are cross-cultural implications for the proposed effects. For example, individualistic cultures "encourage group members to seek out their own interests and view others (especially outgroups) as enemies or competitors" (Rosenberg and Treviño, 2003, p. 163). Thus, it could be possible that socially cohesive teams working in countries with high levels of individualism (e.g., Germany, the United Sates) display stronger intergroup bias than socially cohesive teams of countries with high levels of collectivism (e.g. South Korea).

\section{References}

Aberson, C. L., M. Healy, and V. Romero. 2000. Intragroup bias and self-esteem: A metaanalysis. Personality and Social Psychology Review 4(2): 157-173.

Aiken, L.S. and S.G. West. 1991 Multiple Regression: Testing and Interpreting Interactions, Sage Publications: Newbury Park, CA.

Ali, A., R., Krapfel, and D. LaBahn, D. 1995. Product innovativeness and entry strategy: impact on cycle time and break-even time. Journal of Product Innovation Management 12(1): 54-69.

Ancona, D. G., and D.F. Caldwell. 1988. Beyond task and maintenance: Defining external functions in groups. Group \& Organization Studies 13(4): 468-494.

Ancona, D.G. and D.F. Caldwell. 1992. Bridging the boundary: External activity and performance in organizational teams. Administrative Science Quarterly 37: 634-665.

Ancona, D.G., H. Bresman and D.F. Caldwell. 2009. The X-Factor: Six Steps to Leading HighPerforming X-Teams. Organizational Dynamics 38(3): 217-224.

Bernthal, P. R. and C.A. Insko. 1993. Cohesiveness without groupthink: The interactive effects of social and task cohesion. Group and Organization Management 18(1): 66-87.

Bettenhausen, K. L. 1991. Five years of groups research: What we have learned and what needs 
to be addressed. Journal of Management 17(2): 345-381.

Bresman, H. and M. Zellmer-Bruhn. 2013. The structural context of team learning: Effects of organizational and team structure on internal and external learning. Organization Science 24(4): 1120-1139.

Brion, S., V. Chauvet, B. Chollet and C. Mothe. 2012. Project leaders as boundary spanners: Relational antecedents and performance outcomes. International Journal of Project Management 30(6): 708-722.

Brockman, B.K. and R.M. Morgan. 2003. The role of existing knowledge in new product innovativeness and performance. Decision Sciences 34(2): 385-419.

Brockman, B.K., M.E. Rawlston, M.A. Jones and D. Halstead. 2010. An exploratory model of interpersonal cohesiveness in new product development teams. Journal of Product Innovation Management 27(2): 201-219.

Choi, J.N. 2002. External activities and team effectiveness review and theoretical development. Small Group Research 33(2): 181-208.

Chung, Y. and S.E. Jackson. 2013. The internal and external networks of knowledge-intensive teams: The role of task routineness. Journal of Management 39(2): 442-468.

Cohen, J., P. Cohen, S.G. West and L.S. Aiken. 2013. Applied multiple regression/correlation analysis for the behavioral sciences. Routledge.

Cotec, F. 2016. Informe Cotec 2016: Innovación en España. Foundacion Cotec. Madrid

Dion, K.L. 1973. Cohesiveness as a determinant of ingroup-outgroup bias. Journal of Personality and Social Psychology 28(2): 163-171.

Dokko, G., A.A. Kane and M. Tortoriello. 2014. One of us or one of my friends: How social identity and tie strength shape the creative generativity of boundary-spanning ties. 
Organization Studies 35(5): 703-726.

Drach-Zahavy, A. and A. Somech. 2010. From an intrateam to an interteam perspective of effectiveness: The role of interdependence and boundary activities. Small Group Research 41(2): 143-174.

Evanschitzky, H., M., Eisend, R.J. Calantone, and Y. Jiang. 2012. Success factors of product innovation: An updated meta-analysis. Journal of Product Innovation Management 29(S1): 21-37.

Faraj, S. and A. Yan. 2009. Boundary work in knowledge teams. Journal of Applied Psychology 94(3): 604-617.

Fornell, C. and D. Larcker. 1981. Evaluating structural equation models with unobservable variables and measurement error. Journal of Marketing Research 18: 39-50.

Frazier, P. A., A.P. Tix and K.E. Barron. 2004. Testing moderator and mediator effects in counseling psychology research. Journal of Counseling Psychology 51(1): 115-134

Gaertner, S.L., J.F. Dovidio, M.C. Rust, J.A. Nier, B.S. Banker, Ch.M. Ward, G.R. Mottola and M. Houlette. 1999. Reducing intergroup bias: elements of intergroup cooperation. Journal of Personality and Social Psychology 76(3): 388-402.

García, N., M.J. Sanzo and J.A. Trespalacios. 2008. New product internal performance and market performance: Evidence from Spanish firms regarding the role of trust, interfunctional integration, and innovation type. Technovation 28(11): 713-725.

Gibson, C.B. and R. Dibble. 2013. Excess may do harm: Investigating the effect of team external environment on external activities in teams. Organization Science 24(3): 697-715.

Glynn, M.A., R. Kazanjian and R. Drazin. 2010. Fostering innovation in complex product development settings: The role of team member identity and interteam interdependence. 
Journal of Product Innovation Management 27(7): 1082-1095.

Goodman, P.S., E. Ravlin and M. Schminke. 1987. Understanding groups in organizations. In: Cummings, L.L., Staw, B.M. (Eds.). Research in Organizational Behavior 9: 121-173.

Hair, J.F., W.C. Black, B.J. Babin, and R.E. Anderson 2009. Multivariate Data Analysis, Pearson, 7th edition.

Hair, J.F., G.T. Hult, C.M. Ringle and M. Sarstedt. 2013. A Primer on Partial Least Square Structural Equation Modeling (PLS SEM). Sage publications, United Kingdom.

Henard, D. H., and D.M. Szymanski. 2001. Why some new products are more successful than others. Journal of Marketing Research 38(3): 362-375.

Henseler, J., C.M. Ringle and M. Sarstedt. 2015. A new criterion for assessing discriminant validity in variance-based structural equation modeling. Journal of the Academy of Marketing Science 43 (1): 115-135.

Hewstone, M., M. Rubin and H. Willis. 2002. Intergroup bias. Annual Review of Psychology 53(1): 575-604.

Hogg, M.A. and D. Abrams. 1988. Social identifications: A social psychology of intergroup relations and group processes. London: Routledge.

Hogg, M.A. and D.I. Terry. 2000. Social identity and self-categorization processes in organizational contexts. Academy of Management Review 25(1): 121-140.

Hogg, M.A. and S.C. Hains. 1996. Intergroup relations and group solidarity: Effects of group identification and social beliefs on depersonalized attraction. Journal of Personality and Social Psychology 70(2): 295-309.

Howell, J.M. and C.M. Shea. 2006. Effects of champion behavior, team potency, and external communication activities on predicting team performance. Group and Organization 
Management 31(2): 180-211.

Im, S., M.M. Montoya and J.P. Workman. 2013. Antecedents and consequences of creativity in product innovation teams. Journal of Product Innovation Management 30(1): 170-185.

Janssen, O. 2003. Innovative behaviour and job involvement at the price of conflict and less satisfactory relations with co-workers. Journal of Occupational and Organizational Psychology 76(3): 347-364.

Janssen, O. 2004. How fairness perceptions make innovative behavior more or less stressful. Journal of Organizational Behavior 25(2): 201-215.

Janssen, O., E. Van de Vliert, and M. West. 2004. The bright and dark sides of individual and group innovation: A special issue introduction. Journal of Organizational Behavior 25(2): $129-145$.

Johnson, R.E., C.C. Rosen, C.C. and E. Djurdjevic. 2011. Assessing the impact of common method variance on higher order multidimensional constructs. Journal of Applied Psychology 96(4): 744-761.

Joshi, A., N. Pandy and G.H. Han. 2009. Bracketing team boundary spanning: An examination of task-based, team-level, and contextual antecedents. Journal of Organizational Behavior 30(6): 731-759.

Kim, N. and K. Atuahene-Gima. 2010. Using exploratory and exploitative market learning for new product development. Journal of Product Innovation Management 27(4): 519-536.

Langfred, C.W. 2000. The paradox of self-management: Individual and group autonomy in work groups. Journal of Organizational Behavior 21 (5): 563-585.

Leonardelli, G.J. and M.B. Brewer. 2001. Minority and majority discrimination: When and why. Journal of Experimental Social Psychology 37(6): 468-485. 
Li, T. and R.J. Calantone. 1998. The impact of market knowledge competence on new product advantage: conceptualization and empirical examination. Journal of Marketing 62(4): 13-29.

Man, D.C. and S.S. Lam, 2003. The effects of job complexity and autonomy on cohesiveness in collectivistic and individualistic work groups: a cross-cultural analysis. Journal of Organizational Behavior 24(8): 979-1001.

Marrone, J.A. 2010. Team boundary spanning: A multilevel review of past research and proposals for the future. Journal of Management 36(4): 911-940.

Maurer, I., V. Bartsch and M. Ebers. 2011. The value of intra-organizational social capital: How it fosters knowledge transfer, innovation performance, and growth. Organization Studies 32(2): 157-185.

McNally, R.C., E. Cavusgil and R. Calantone. 2010. Product innovativeness dimensions and their relationships with product advantage, product financial performance and project protocol. Journal of Product Innovation Management 27: 991-1006.

Menon, A., B.J. Jaworski and A.K. Kohli. 1997. Product quality: Impact of interdepartmental interactions. Journal of the Academy of Marketing Science 25(3): 187-200.

Nakata, C. and S. Im. 2010. Spurring cross-functional integration for higher new product performance: A group effectiveness perspective. Journal of Product Innovation Management, 27(4): 554-571.

Nunnally, J.C. and I.H. Bernstein. 1994. Psychometric Theory, $3^{\text {rd }}$ ed. New York: McGraw-Hill.

Oh, H., G. Labianca and M.H. Chung. 2006. A multilevel model of group social capital. Academy of Management Review 31(3): 569-582.

Oh, H., M.H. Chung, M. H. and G. Labianca. 2004. Group social capital and group effectiveness: The role of informal socializing ties. Academy of Management Journal 47(6): 860-875. 
Petersen, L.E., J. Dietz and D. Frey. 2004. The effects of intragroup interaction and cohesion on intergroup bias. Group Processes and Intergroup Relations 7(2): 107-118.

Podsakoff, P.M., S.B. MacKenzie, J.Y. Lee and N.P Podsakoff. 2003. Common method biases in behavioral research: A critical review of the literature and recommended remedies. Journal of Applied Psychology 88(5): 879-903.

Potter, A. and B. Lawson. 2013. Help or hindrance? Causal ambiguity and supplier involvement in new product development teams. Journal of Product Innovation Management 30(4): 794808.

Reinartz, W., M. Haenlein and J. Henseler. 2009. An empirical comparison of the efficacy of covariance-based and variance-based SEM. International Journal of Research in Marketing 26(4): 332-344.

Rempel, M.W. and R.J. Fisher. 1997. Perceived threat, cohesion, and group problem solving in intergroup conflict. International Journal of Conflict Management 8(3): 216-234.

Riccobono, F., M. Bruccoleri and A. Größler. 2016. Groupthink and Project Performance: The Influence of Personal Traits and Interpersonal Ties. Production and Operations Management 25(4): 609-629.

Richter, A.W., J. Scully and M.A. West. 2005. Intergroup conflict and intergroup effectiveness in organizations: Theory and scale development. European Journal of Work and Organizational Psychology 14: 177-203.

Richter, A.W., M.A. West, R. Van Dick and J.F. Dawson. 2006. Boundary spanners' identification, intergroup contact, and effective intergroup relations. Academy of Management Journal 49(6): 1252-1269.

Rindfleisch, A., A.J. Malter, S. Ganesan, and C. Moorman. 2008. Cross-sectional versus 
longitudinal survey research: Concepts, findings, and guidelines. Journal of Marketing Research 45(3): 261-279.

Rosenberg, A.S. and L.K. Treviño. 2003. A proposed model of between-group helping: An identity-based approach. Journal of Managerial Issues 15(2) (Summer): 154-174.

Schoonhoven, C.B. 1981. Problems with contingency theory: Testing assumptions hidden within the language of contingency theory. Administrative Science Quarterly 26(3): 349-377.

Sethi, R. 2000. Superordinate identity in cross-functional product development teams: Its antecedents and effect on new product performance. Journal of the Academy of Marketing Science 28(3): 330-344.

Sethi, R., D.C. Smith and C.W. Park. 2001. Cross-functional product development teams, creativity, and the innovativeness of new consumer products. Journal of Marketing Research 38(1): 73-85.

Shaner, M.B., L. Beeler and C.H. Noble. 2016. Do we have to get along to innovate? The influence of multilevel social cohesion on new product and new service development. Journal of Product Innovation Management 33(S1): 148-165.

Siguaw, J.A., P.M. Simpson and C.A. Enz. 2006. Conceptualizing innovation orientation: A framework for study and integration of innovation research. Journal of Product Innovation Management 23(6): 556-574.

Sleep, S., S. Bharadwaj and S.K. Lam. 2015. Walking a tightrope: the joint impact of customer and within-firm boundary spanning activities on perceived customer satisfaction and team performance. Journal of the Academy of Marketing Science 43(4): 472-489.

Song, X.M, and M.M. Montoya-Weiss. 2001. The effect of perceived technological uncertainty on Japanese new product development. Journal of Academy Management 44: 61-80. 
Tajfel, H. 1982. Social psychology of intergroup relations. Annual Review of Psychology 33(1): $1-39$.

Tajfel, H., and J.C. Turner 1979. An integrative theory of intergroup conflict. In W. G. Austin, \& S. Worchel (Eds.), The social psychology of intergroup relations (pp. 33-37). Monterey, CA: Brooks/Cole.

Tajfel, H. and J.C. Turner. 1986. The social identity theory of inter group behavior in S Worchel and WG Austin (Eds) Psychology of intergroup relations. Chicago: Nelson.

Tellis, G.J., J.C. Prabhu and R.K. Chandy. 2009. Radical innovation across nations: The preeminence of corporate culture. Journal of Marketing 73(1): 3-23.

Turner, M.E. and A.R. Pratkanis. 1998. A social identity maintenance model of groupthink. Organizational Behavior and Human Decision Processes 73(2): 210-235.

Turner, M.E., A.R. Pratkanis, P. Probasco and C. Leve. 1992. Threat, cohesion, and group effectiveness: Testing a social identity maintenance perspective on groupthink. Journal of Personality and Social Psychology 63(5): 781-796.

Turner, M.E., and T. Horvitz, T. 2001. The dilemma of threat: Group effectiveness and ineffectiveness under adversity. In M. Turner (Ed.) Groups at Work: Theory and Research: 445-470. Mahwah, N.J.: Erlbaum.

Veldhuizen, E., E.J. Hultink and A. Griffin. 2006. Modeling market information processing in new product development: An empirical analysis. Journal of Engineering and Technology Management 23(4): 353-373.

Williams, M. 2001. In whom we trust: Group membership as an affective context for trust development. Academy of Management Review 26(3): 377-396.

Zahra, S.A. 1993. Environment, corporate entrepreneurship, and financial performance: A 
taxonomic approach. Journal of Business Venturing 8(4): 319-340. 
Figure 1

Conceptual Framework

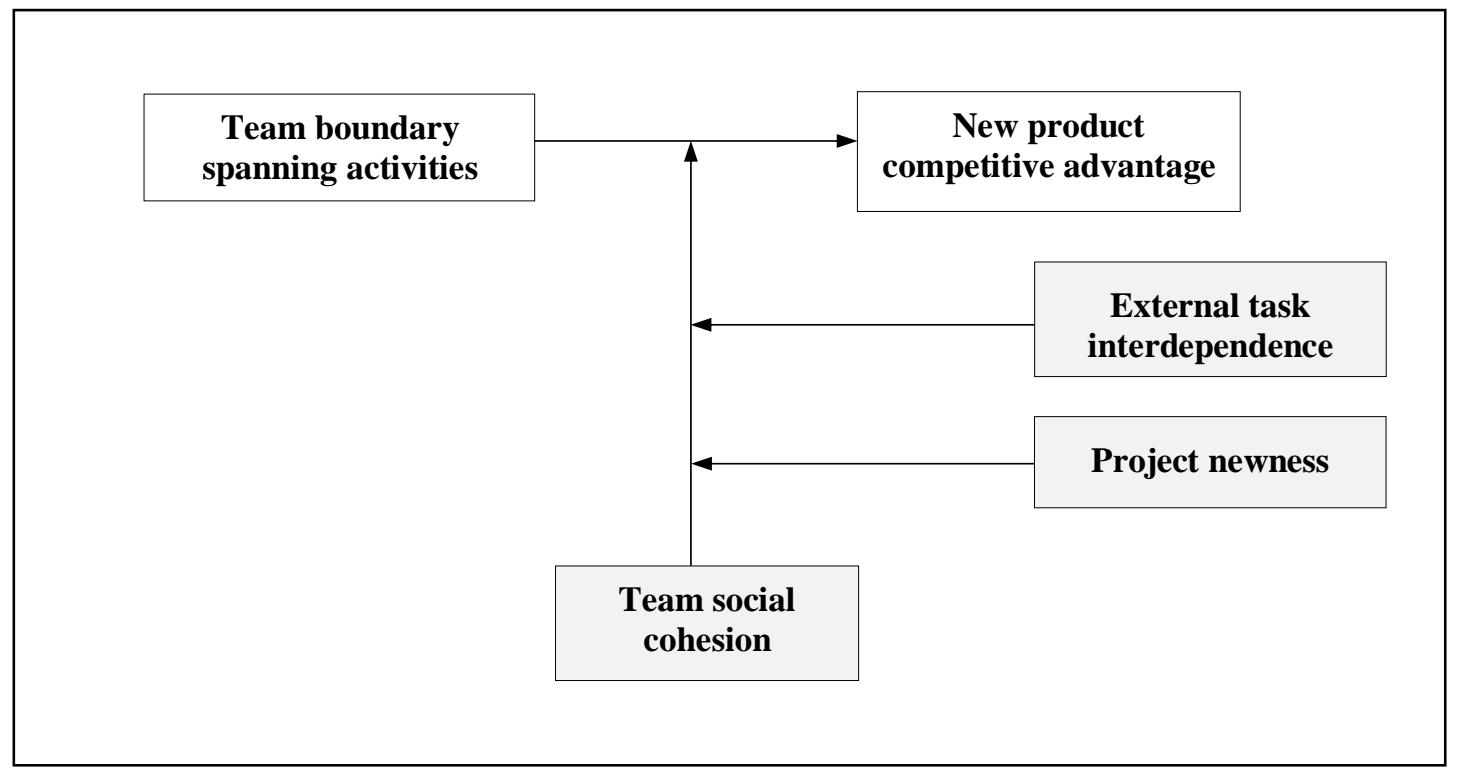


Table 1

Population and sample distribution by industry: Proportion test

\begin{tabular}{|c|c|c|c|c|c|c|}
\hline \multirow[t]{2}{*}{ NAICS codes } & \multirow[t]{2}{*}{ Industrial sector } & \multirow{2}{*}{$\begin{array}{l}\text { Amadeus } \\
\text { directory }\end{array}$} & \multicolumn{2}{|c|}{ Population } & \multicolumn{2}{|c|}{ Sample } \\
\hline & & & $\mathbf{N}$ & $\begin{array}{l}\% \text { of } \\
\text { total }\end{array}$ & $\mathbf{N}$ & $\begin{array}{l}\% \text { of } \\
\text { total }\end{array}$ \\
\hline 311,312 & Food and beverages manufacturing & 813 & 203 & $21.5 \%$ & 23 & $16.4 \%$ \\
\hline 325,326 & Chemical and plastics product manufacturing & 851 & 213 & $22.5 \%$ & 36 & $25.7 \%$ \\
\hline 333 & Machinery manufacturing & 490 & 122 & $12.9 \%$ & 15 & $10.7 \%$ \\
\hline $327,331,332$ & $\begin{array}{l}\text { Non-metallic mineral product, primary metal and } \\
\text { fabricated metal product manufacturing }\end{array}$ & 781 & 195 & $20.6 \%$ & 21 & $15.0 \%$ \\
\hline 334,335 & Computer, electronic, and electrical manufacturing & 434 & 109 & $11.5 \%{ }^{*}$ & 28 & $20.0 \%{ }^{*}$ \\
\hline 336 & Transportation equipment manufacturing & 417 & 104 & $11.0 \%$ & 17 & $12.1 \%$ \\
\hline & TOTAL & 3786 & 946 & $100 \%$ & 140 & $100 \%$ \\
\hline
\end{tabular}

* Significant differences: $\mathrm{p}<0.05$ 
Table 2

Team boundary spanning dimensions ${ }^{1}$

$\begin{array}{cc}\text { Mean(S.D.) } & \begin{array}{c}\text { Factor } \\ \text { loading } \\ \text { (from CFA) }\end{array}\end{array}$

FACTOR 1. INTRA-FIRM AMBASSADOR $(\alpha=0.81 ; \mathrm{CR}=0.87$; AVE $=0.58)$

I_AMB1: Project leader or team members talked up the NPD project to individuals or groups 5.59 (1.31)

0.823

in the company.

I_AMB2: Persuaded them that the NPD project was important.

$5.63(1.24) \quad 0.808$

I_AMB3: Persuaded them to support the team's activities and decisions.

$5.30(1.24) \quad 0.835$

I AMB4: Kept them informed of the progress on the team's activities to gain support for the $5.54(1.17) \quad 0.640$ project.

I_AMB5: Built relationship with these groups.

$5.21(1.21) \quad 0.682$

FACTOR 2. EXTRA-FIRM AMBASSADOR $(\alpha=0.91 ; \mathrm{CR}=0.92 ; \mathrm{AVE}=0.73)$

E_AMB1: Project leader or team members talked up the NPD project to individuals or groups $5.01(1.69) \quad 0.870$

outside the company.

E_AMB2: Persuaded them that the NPD project was important. $\quad 4.85(1.76)$

E_AMB3: Persuaded them to support the team's activities and decisions. $\quad 4.34$ (1.84) 0.871

E_AMB4: Kept them informed of the progress on the team's activities to gain support for the $4.27(1.62) \quad 0.813$

project.

E_AMB5: Built relationship with these groups.

$4.99(1.69) \quad 0.818$

FACTOR 3. INTRA-FIRM SCOUTING-1 ( $\mathrm{r}=0.62 ; \mathrm{CR}=0.89$; AVE=0.81)

I_SCOUT1. Found out whether individuals or groups inside the company supported the $4.97(1.44) \quad 0.903$ team's activities

I_SCOUT2. Found out their expectations about the new product project

$5.26(1.29) \quad 0.896$

FACTOR 4. INTRA-FIRM SCOUTING-2 ( $\mathrm{r}=0.66 ; \mathrm{CR}=0.91 ; \mathrm{AVE}=0.83)$

I_SCOUT3: Inquired them about new or emergent marketing information and trends.

$4.85(1.54)$

0.929

I_SCOUT4: Inquired them about new or emergent technical information and trends.

$4.72(1.70)$

0.890

I_SCOUT5: Collected their perceptions about the team and project's progress ${ }^{\text {a }}$

I_SCOUT6: Inquired them about information regarding the company's strategy and climate that could impact the NPD project ${ }^{\text {a }}$

FACTOR 5. EXTRA-FIRM SCOUTING $(\alpha=0.90 ; \mathrm{CR}=0.92 ; \mathrm{AVE}=0.67)$

E_SCOUT1: Found out whether individuals or groups outside the company supported the

team's activities.

E_SCOUT2: Found out their expectations about the new product project.

$4.64(1.87) \quad 0.861$

E_SCOUT3: Inquired them about new or emergent marketing information and trends.

$4.69(1.88) \quad 0.826$

E_SCOUT4: Inquired them about new or emergent technical information and trends.

$4.84(1.71) \quad 0.844$

E_SCOUT5: Collected their perceptions about the team and project's progress.

$4.24(1.88) \quad 0.756$

E_SCOUT6: Inquired them about information regarding changes or early signs of trouble in

$4.93(1.79)$

0.814

the external environment 
FACTOR 6. INTRA-FIRM TASK COORDINATION $(\alpha=0.75 ; \mathrm{CR}=0.85 ; \mathrm{AVE}=0.66)$

I_COORD1. Negotiated resources (time, money, people) for the team with groups inside the company ${ }^{\text {a }}$

I_COORD2. Coordinated with them development and commercialization activities with

other individuals or departments.

I_COORD3. Resolved with them technical and marketing problems that aroused during the development process.

I_COORD4. Reviewed with them product concepts, preliminary product designs and ideas

for marketing plans.

FACTOR 7. EXTRA-FIRM TASK COORDINATION $(\alpha=0.84 ; \mathrm{CR}=0.89 ; \mathrm{AVE}=0.68)$

E_COORD1. Procured knowledge and skills relevant to the NPD project from groups

outside the company.

E_COORD2. Coordinated with them development and commercialization activities with

interested parties

E_COORD3. Resolved with them technical and marketing problems that aroused during

$4.47(1.72)$

0.902

the development.

E_COORD4. Reviewed with them product concepts, preliminary product designs and

0.864 ideas for marketing plans

${ }^{1}$ Source: Ancona and Caldwell (1988 and 1992)

NOTE. Items were measured with 7-point scale where 1 is "totally disagree" and 7 "completely agree".

CFA: Confirmatory Factor Analysis.

${ }^{a}$ Items eliminated after exploratory analysis.

$\alpha$ : Cronbach's alpha; r: correlation value; CR: Composite Reliability; AVE: Average Variance Extracted. 
Table 3

Quality criteria of formative measurement

\begin{tabular}{llll}
\hline $\begin{array}{l}\text { Formative second-order } \\
\text { construct }\end{array}$ & \multicolumn{1}{c}{ Dimensions } & Outer weights & $\mathrm{VIF}^{1}$ \\
\hline $\begin{array}{l}\text { Team boundary } \\
\text { spanning }\end{array}$ & 1. Intrafirm ambassador & $0.415^{* *}$ & 1.541 \\
& 2. Extrafirm ambassador & $0.793^{* *}$ & 1.935 \\
& 3. Intrafirm scouting-1 & $0.177^{* *}$ & 1.520 \\
& 4. Intrafirm scouting-2 & $0.219^{* *}$ & 1.396 \\
& 5. Extrafirm scouting & $0.807^{* *}$ & 2.198 \\
& 6. Intrafirm task coordination & $0.414^{* *}$ & 1.285 \\
& 7. Extrafirm task coordination & $0.761^{* *}$ & 1.860
\end{tabular}

Bias-corrected bootstrap significance levels: $* * \mathrm{p}<.01, * \mathrm{p}<.05$ (one-tailed test).

${ }^{1}$ VIF: Variance Inflation Factor. 
Table 4

Measurement scales for moderators, outcomes and control variables

\begin{tabular}{|c|c|c|}
\hline & Mean (S.D.) & $\begin{array}{l}\text { Factor loadings } \\
\text { (from CFA) }\end{array}$ \\
\hline \multicolumn{3}{|l|}{ SOCIAL TEAM COHESION (Sethi et al., 2001) $(\alpha=0.88, \mathrm{AVE}=0.74, \mathrm{CR}=0.92)$} \\
\hline Member of the NPD team were very comfortable with each other. & $5.52(1.09)$ & 0.901 \\
\hline Members of the NPD team were very friendly with each other. & $5.48(1.05)$ & 0.860 \\
\hline Our team had a very pleasant working atmosphere. & $5.36(1.09)$ & 0.926 \\
\hline Members of the team took a personal interest in one another. & $4.75(1.38)$ & 0.739 \\
\hline \multicolumn{2}{|l|}{ EXTERNAL TASK INTERDEPENDENCE (Sethi, 2000) $(\alpha=0.83$, AVE $=0.74$, } & 0.866 \\
\hline $\begin{array}{l}\text { On this project, members were dependent on the information and expertise of } \\
\text { individuals external to the team to successfully do their jobs. }\end{array}$ & $4.35(1.62)$ & 0.881 \\
\hline $\begin{array}{l}\text { Members were dependent on the cooperation of individuals outside the team to } \\
\text { successfully do their jobs. }\end{array}$ & $4.34(1.76)$ & 0.841 \\
\hline \multicolumn{3}{|l|}{$\begin{array}{l}\text { Members were required to jointly make important project-related decisions with } \\
\text { individuals outside the team. }\end{array}$} \\
\hline \multicolumn{3}{|l|}{ PROJECT NEWNESS (McNally et al., 2010) $(\alpha=0.74, \mathrm{AVE}=0.66, \mathrm{CR}=0.85)$} \\
\hline The product category was new to the company. & $5.27(2.03)$ & 0.655 \\
\hline The product could not have been manufactured using existing company equipment. & $3.61(2.18)$ & 0.858 \\
\hline $\begin{array}{l}\text { The technology used in the development of this product was not familiar to the } \\
\text { company. }\end{array}$ & $3.76(2.02)$ & 0.908 \\
\hline \multicolumn{2}{|l|}{ NEW PRODUCT COMPETITIVE ADVANTAGE (McNally et al., 2010) $(\alpha=0.81$; } & 0.893 \\
\hline The product is superior to competing products in terms of meeting customers' needs. & $5.44(1.35)$ & 0.883 \\
\hline The quality perceived by the users is superior to competitive products. & $5.49(1.46)$ & 0.768 \\
\hline \multicolumn{3}{|l|}{$\begin{array}{l}\text { The product offers the customer unique attributes or performance characteristics not } \\
\text { available from competitive products. }\end{array}$} \\
\hline \multicolumn{3}{|l|}{ FIRM SIZE } \\
\hline Number of employees & $529.1(1177.8)$ & - \\
\hline \multicolumn{3}{|l|}{ PRODUCT INNOVATION (Zahra, 1993) $(\alpha=0.82 ; \mathrm{AVE}=0.74, \mathrm{CR}=0.89)$} \\
\hline $\begin{array}{l}\text { We renew the product portfolio by continually launching new and improved } \\
\text { products. }\end{array}$ & $5.26(1.61)$ & 0.922 \\
\hline We invest a significant amount of resources in new product development activities. & $4.97(1.66)$ & 0.891 \\
\hline $\begin{array}{l}\text { A nign percentage of the company s revenues came irom new products introduced } \\
\text { during the last two years. }\end{array}$ & $4.51(1.68)$ & 0.755 \\
\hline
\end{tabular}

NOTE. Items were measured with 7-point scale where 1 is "totally disagree" and 7 "completely agree".

CFA: Confirmatory Factor Analysis

$\alpha$ : Cronbach's alpha; CR: Composite Reliability; AVE: Average Variance Extracted 
Table 5

Zero-order correlations and discriminant validity (HTMT ratios) ${ }^{(*)}$

\begin{tabular}{lccccccc}
\hline & 1 & 2 & 3 & 4 & 5 & 6 & 7 \\
\hline 1. Team boundary spanning & n.a. & 0.15 & 0.25 & 0.19 & 0.19 & 0.15 & 0.18 \\
2. Team social cohesion & -0.01 & 0.86 & 0.16 & 0.05 & 0.29 & 0.05 & 0.08 \\
3. External task interdependence & $0.24^{* *}$ & -0.16 & 0.86 & 0.31 & 0.14 & 0.16 & 0.13 \\
4. Project newness & $0.18^{*}$ & 0.05 & $0.31^{* *}$ & 0.81 & 0.18 & 0.23 & 0.12 \\
5. NP competitive advantage & 0.15 & $0.27^{* *}$ & -0.05 & 0.12 & 0.85 & 0.14 & 0.31 \\
6. Firm size & 0.11 & 0.05 & $0.16^{*}$ & $0.23^{* *}$ & -0.01 & $n . a$. & 0.18 \\
7. Product innovation & 0.05 & 0.09 & -0.01 & -0.10 & $0.27^{* *}$ & $0.18^{* *}$ & 0.86 \\
\hline
\end{tabular}

Significance levels: $* * \mathrm{p}<.01,{ }^{*} \mathrm{p}<.05$.

${ }^{(*)}$ The italic values on the diagonal show the square root of AVE.

Values below the diagonal are the correlations between constructs and the values above the diagonal are the HTMT ratios. 
Table 6

Standardized parameter estimates

\begin{tabular}{|c|c|c|c|c|}
\hline & Model 1 & Model 2 & Model 3 & Model 4 \\
\hline \multicolumn{5}{|l|}{ Hypothesized relationships } \\
\hline Team boundary spanning $\rightarrow$ NP competitive advantage & $0.14^{*}(\mathrm{H} 1)$ & $0.20^{* *}$ & $0.19^{* *}$ & $0.20^{* *}$ \\
\hline $\begin{array}{l}\text { Team boundary spanning } * \text { Team social cohesion } \rightarrow \text { NP } \\
\text { competitive advantage }\end{array}$ & & $-0.24^{* *}(\mathrm{H} 2)$ & $-0.27^{* *}$ & $-0.28^{* *}$ \\
\hline Team boundary spanning $*$ Team social cohesion $*$ & & & $-0.28^{* *}(\mathrm{H} 3)$ & \\
\hline \multicolumn{5}{|l|}{$\begin{array}{l}\text { External task interdependence } \rightarrow \text { NP competitive } \\
\text { advantage }\end{array}$} \\
\hline Team boundary spanning $*$ Team social cohesion $*$ & & & & $-0.19^{*}(\mathrm{H} 4)$ \\
\hline \multicolumn{5}{|l|}{ Project newness $\rightarrow$ NP competitive advantage } \\
\hline \multicolumn{5}{|l|}{ Control relationships } \\
\hline Firm size $\rightarrow$ NP competitive advantage & -0.11 & -0.11 & -0.07 & -0.06 \\
\hline Product innovation $\rightarrow$ NP competitive advantage & $0.29^{* *}$ & $0.30^{* *}$ & $0.28^{* *}$ & $0.30^{* *}$ \\
\hline Team social cohesion $\rightarrow$ NP competitive advantage & $0.23^{* *}$ & $0.23^{* *}$ & $0.32^{* *}$ & $0.32^{* *}$ \\
\hline $\begin{array}{l}\text { External team interdependence } \rightarrow \text { NP competitive } \\
\text { advantage }\end{array}$ & -0.07 & -0.05 & -0.05 & -0.08 \\
\hline Project newness $\rightarrow$ NP competitive advantage & $0.16^{*}$ & $0.16^{*}$ & 0.14 & 0.14 \\
\hline Team social cohesion $*$ External task interdependence & & & -0.03 & \\
\hline$\rightarrow$ NP competitive advantage & & & & \\
\hline $\begin{array}{l}\text { Team boundary spanning } * \text { External task } \\
\text { interdependence } \rightarrow \text { NP competitive advantage }\end{array}$ & & & $-0.18^{*}$ & \\
\hline $\begin{array}{l}\text { Team social cohesion } * \text { Project newness } \rightarrow \text { NP } \\
\text { competitive advantage }\end{array}$ & & & & -0.05 \\
\hline $\begin{array}{l}\text { Team boundary spanning } * \text { Project newness } \rightarrow \text { NP } \\
\text { competitive advantage }\end{array}$ & & & & -0.13 \\
\hline $\mathrm{R}^{2} \mathrm{NP}$ competitive advantage & 0.18 & 0.23 & 0.29 & 0.29 \\
\hline
\end{tabular}

Significance levels: * p<.05 (one-tailed test).

NOTE: The highest VIF (variation inflation factor) for Model 1, 2, 3 and 4 are, respectively, 1.196, 1.210, 1.769 and 1.341 
Figure 2

The impact of external task interdependence on the effect that team social cohesion has on the relationships between boundary spanning (BS) activities and new product competitive advantage

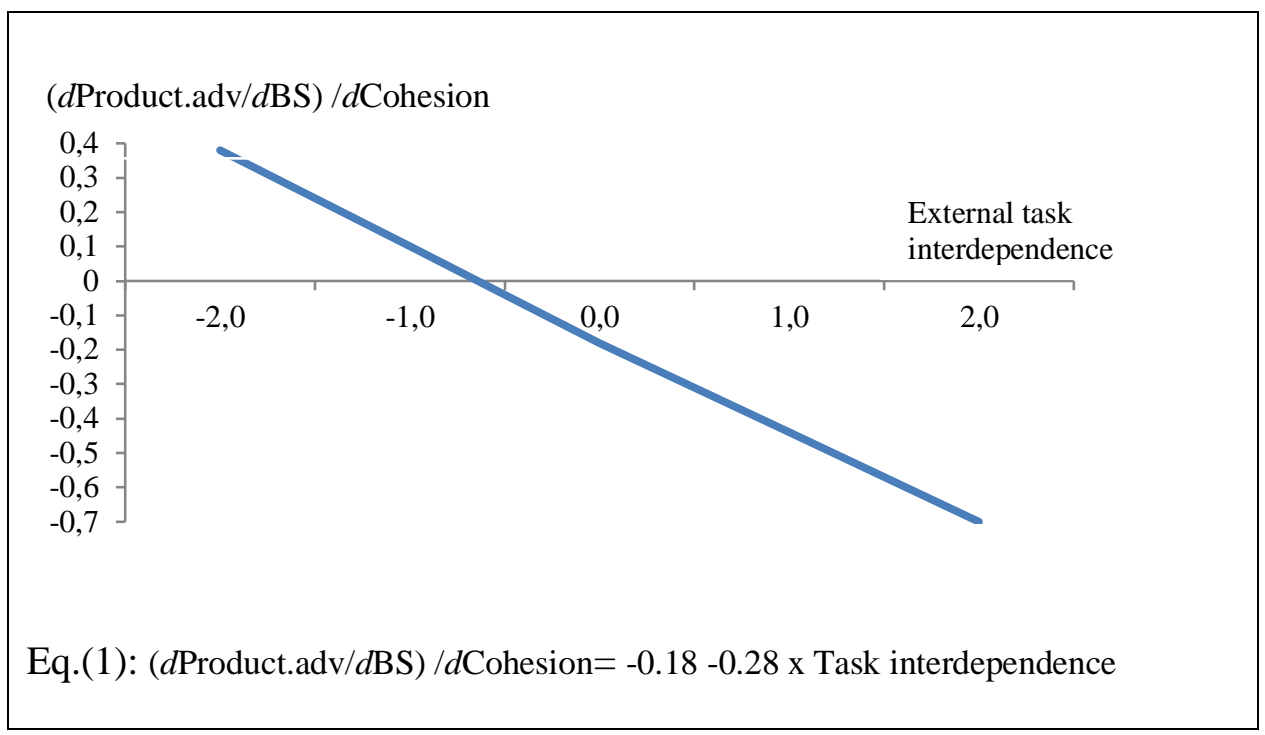

Figure 3

The impact of project newness on the effect that team social cohesion has on the relationships between boundary spanning activities and new product competitive advantage

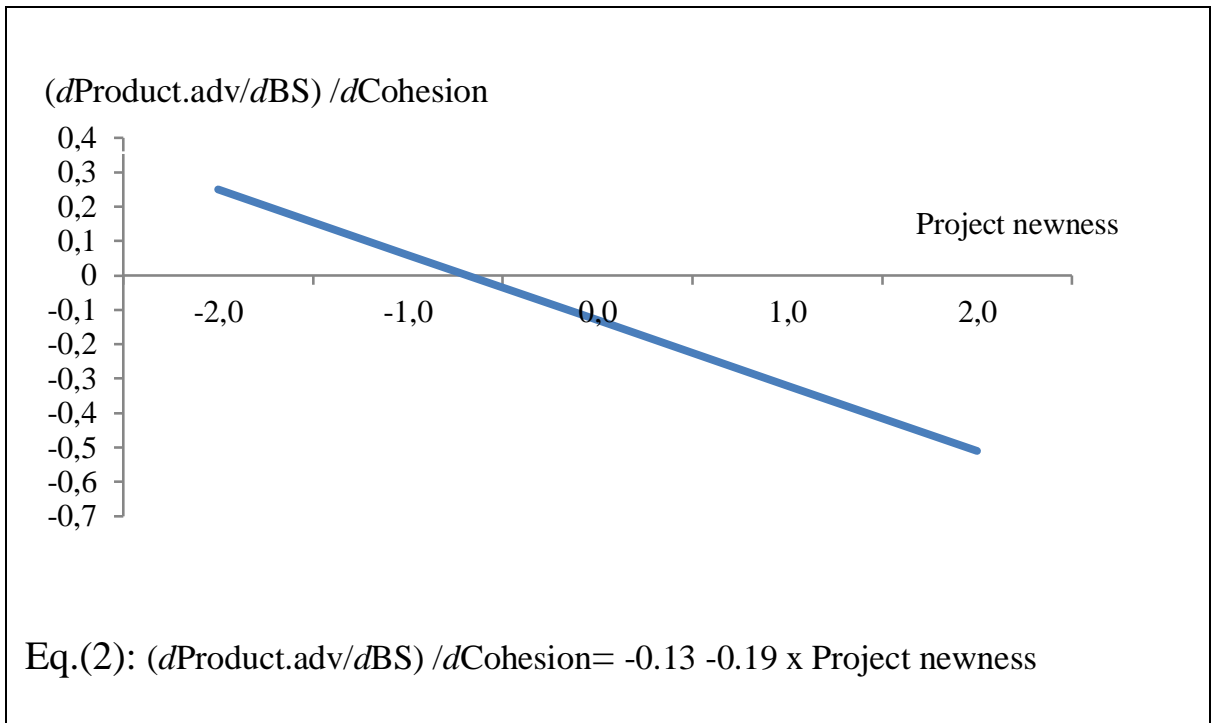




\section{Appendix}

\section{Standardized Parameter Estimates for Ambassador Activities}

\begin{tabular}{|c|c|c|c|c|}
\hline & Model 1 & Model 2 & Model 3 & Model 4 \\
\hline \multicolumn{5}{|l|}{ Hypothesized relationships } \\
\hline Ambassador $\rightarrow$ NP comp. adv. & $0.13^{*}$ & $0.17^{*}$ & $0.15^{*}$ & $0.16^{*}$ \\
\hline Ambassador $*$ Social cohesion $\rightarrow$ NP comp. adv. & & $-0.18^{*}$ & $-0.21^{*}$ & $-0.26^{* *}$ \\
\hline Ambassador $*$ Social cohesion $*$ External task interdependence $\rightarrow$ & & & $-0.14^{*}$ & \\
\hline \multicolumn{5}{|l|}{ NP comp. adv. } \\
\hline $\begin{array}{l}\text { Ambassador } * \text { Social cohesion } * \text { Project newness } \rightarrow \text { NP comp. } \\
\text { adv. }\end{array}$ & & & & $-0.22^{* *}$ \\
\hline \multicolumn{5}{|l|}{ Control relationships } \\
\hline Firm size $\rightarrow$ NP comp. adv. & -0.12 & -0.11 & -0.09 & -0.08 \\
\hline Product innovation $\rightarrow$ NP comp. adv. & $0.28^{* *}$ & $0.28^{* *}$ & $0.28^{* *}$ & $0.30^{* *}$ \\
\hline Team social cohesion $\rightarrow$ NP comp. adv. & $0.23^{* *}$ & $0.23^{* *}$ & $0.28^{* * *}$ & $0.20^{*}$ \\
\hline External team interdependence $\rightarrow$ NP comp. adv. & -0.09 & -0.07 & -0.05 & -0.09 \\
\hline Project newness $\rightarrow$ NP comp. adv. & $0.17^{*}$ & $0.17^{*}$ & $0.15^{*}$ & $0.20^{*}$ \\
\hline Social cohesion $*$ External task interdependence $\rightarrow$ NP comp. adv. & & & -0.04 & \\
\hline Ambassador $*$ External task interdependence $\rightarrow$ NP comp. adv. & & & -0.04 & \\
\hline Social cohesion * Project newness $\rightarrow$ NP comp. adv. & & & & -0.09 \\
\hline Ambassador $*$ Project newness $\rightarrow$ NP comp. adv. & & & & -0.06 \\
\hline $\mathrm{R}^{2} \mathrm{NP}$ competitive advantage & 0.18 & 0.20 & 0.24 & 0.25 \\
\hline
\end{tabular}

Significance levels: ${ }^{* *} \mathrm{p}<.01$ (one-tailed test), ${ }^{*} \mathrm{p}<.05$ (one-tailed test), ${ }^{+} \mathrm{p}<.10$ (one-tailed test)

Standardized Parameter Estimates for Scouting Activities

\begin{tabular}{|c|c|c|c|c|}
\hline & \multicolumn{4}{|c|}{ Scouting } \\
\hline & Model 1 & Model 2 & Model 3 & Model 4 \\
\hline \multicolumn{5}{|l|}{ Hypothesized relationships } \\
\hline Scouting $\rightarrow$ NP comp. adv. & $0.16^{*}$ & $0.22^{* *}$ & $0.20^{* *}$ & $0.21^{* *}$ \\
\hline Scouting * Social cohesion $\rightarrow$ NP comp. adv. & & $-0.22^{* *}$ & $-0.24^{*}$ & $-0.26^{* *}$ \\
\hline Scouting $*$ Social cohesion $*$ External task interdependence $\rightarrow$ & & & $-0.13^{*}$ & \\
\hline \multicolumn{5}{|l|}{ NP comp. adv. } \\
\hline Scouting $*$ Social cohesion $*$ Project newness $\rightarrow$ NP comp. adv. & & & & -0.05 \\
\hline \multicolumn{5}{|l|}{ Control relationships } \\
\hline Firm size $\rightarrow$ NP comp. adv. & -0.10 & -0.11 & -0.07 & -0.07 \\
\hline Product innovation $\rightarrow$ NP comp. adv. & $0.25^{* *}$ & $0.28^{* *}$ & $0.26^{* *}$ & $0.30^{\text {** }}$ \\
\hline Team social cohesion $\rightarrow$ NP comp. adv. & $0.24^{* *}$ & $0.25^{* *}$ & $0.30^{*}$ & $0.27^{* *}$ \\
\hline External team interdependence $\rightarrow$ NP comp. adv. & -0.07 & -0.04 & -0.02 & -0.05 \\
\hline Project newness $\rightarrow$ NP comp. adv. & $0.16^{*}$ & $0.17^{*}$ & $0.15^{*}$ & $0.20^{*}$ \\
\hline Social cohesion $*$ External task interdependence $\rightarrow$ NP comp. & & & -0.04 & \\
\hline adv. & & & -0.11 & \\
\hline Scouting * External task interdependence $\rightarrow$ NP comp. adv. & & & & -0.09 \\
\hline Social cohesion $*$ Project newness $\rightarrow$ NP comp. adv. & & & & -0.05 \\
\hline \multicolumn{5}{|l|}{ Scouting $*$ Project newness $\rightarrow$ NP comp. adv. } \\
\hline $\mathrm{R}^{2} \mathrm{NP}$ competitive advantage & 0.19 & 0.23 & 0.27 & 0.28 \\
\hline
\end{tabular}

Significance levels: ${ }^{* *} \mathrm{p}<.01$ (one-tailed test), ${ }^{*} \mathrm{p}<.05$ (one-tailed test), ${ }^{+} \mathrm{p}<.10$ (one-tailed test) 
Standardized Parameter Estimates for Task Coordination Activities

\begin{tabular}{|c|c|c|c|c|}
\hline & \multicolumn{4}{|c|}{ Task coordination } \\
\hline & Model 1 & Model 2 & Model 3 & Model 4 \\
\hline \multicolumn{5}{|l|}{ Hypothesized relationships } \\
\hline Task coordination $\rightarrow$ NP comp. adv. & 0.03 & 0.04 & 0.07 & $0.10^{+}$ \\
\hline Task coordination $*$ Social cohesion $\rightarrow$ NP comp. adv. & & $-0.22^{* *}$ & $-0.25^{* *}$ & $-0.25^{* *}$ \\
\hline Task coordination $*$ Social cohesion $*$ External task & & & $-0.33^{* *}$ & \\
\hline interdependence $\rightarrow$ NP comp. adv. & & & & \\
\hline $\begin{array}{l}\text { Task coordination } * \text { Social cohesion } * \text { Project newness } \rightarrow \text { NP } \\
\text { comp. adv. }\end{array}$ & & & & $-0.29^{* *}$ \\
\hline \multicolumn{5}{|l|}{ Control relationships } \\
\hline Firm size $\rightarrow$ NP comp. adv. & -0.11 & -0.10 & -0.07 & -0.07 \\
\hline Product innovation $\rightarrow$ NP comp. adv. & $0.27^{* *}$ & $0.28^{* *}$ & $0.26^{* *}$ & $0.24^{* *}$ \\
\hline Team social cohesion $\rightarrow$ NP comp. adv. & $0.23^{* *}$ & $0.21^{* *}$ & $0.31^{* *}$ & $0.24^{* *}$ \\
\hline External team interdependence $\rightarrow$ NP comp. adv. & -0.06 & -0.04 & -0.09 & -0.08 \\
\hline Project newness $\rightarrow$ NP comp. adv. & $0.17^{*}$ & $0.18^{*}$ & $0.17^{*}$ & $0.19^{*}$ \\
\hline $\begin{array}{l}\text { Social cohesion } * \text { External task interdependence } \rightarrow \text { NP comp. } \\
\text { adv. }\end{array}$ & & & -0.04 & \\
\hline $\begin{array}{l}\text { Task coordination } * \text { External task interdependence } \rightarrow \mathrm{NP} \\
\text { comp. adv. }\end{array}$ & & & 0.06 & \\
\hline Social cohesion $*$ Project newness $\rightarrow$ NP comp. adv. & & & & -0.09 \\
\hline Task coordination $*$ Project newness $\rightarrow$ NP comp. adv. & & & & -0.05 \\
\hline $\mathrm{R}^{2} \mathrm{NP}$ competitive advantage & 0.16 & 0.21 & 0.30 & 0.28 \\
\hline
\end{tabular}

Significance levels: ${ }^{* *} \mathrm{p}<.01$ (one-tailed test), ${ }^{*} \mathrm{p}<.05$ (one-tailed test), ${ }^{+} \mathrm{p}<.10$ (one-tailed test) 
${ }^{i}$ At the suggestion of one reviewer, we also examined the possibility of a curvilinear moderating effect of team social cohesion on the relationship between team boundary spanning and new product competitive advantage. However, we did not find support for such effect. The interaction effect of boundary spanning and the squared term of team social cohesion was not significant. 